\title{
Research on Risk Assessment of Corporate Social Responsibility Based on Hesitant Fuzzy Language- Cloud Model
}

Liqi Yi ( $\sim$ kg1995538530@163.com )

North China Electric Power University - Beijing Campus: North China Electric Power University

Tao Li

North China Electric Power University - Beijing Campus: North China Electric Power University

\section{Yunfen Guo}

North China Electric Power University - Beijing Campus: North China Electric Power University

Ang Li

North China Electric Power University - Beijing Campus: North China Electric Power University

Ting Zhang

North China Electric Power University - Beijing Campus: North China Electric Power University

Jing Shen

State Grid Zhejiang Electric Power Company Hangzhou Power Supply Company

\section{Research Article}

Keywords: CSR, risk assessment, hesitation fuzzy language, cloud model

Posted Date: September 13th, 2021

DOl: https://doi.org/10.21203/rs.3.rs-811143/v1

License: (9) (i) This work is licensed under a Creative Commons Attribution 4.0 International License.

Read Full License 


\title{
Research on Risk Assessment of Corporate Social Responsibility Based on Hesitant Fuzzy Language-Cloud Model
}

\author{
Liqi $\mathrm{Yi}^{1,}{ }^{*}$, Tao $\mathrm{Li}^{1}$, Yunfen $\mathrm{Guo}^{1}$, Ang $\mathrm{Li}^{1}$, Ting Zhang ${ }^{1}$, Jing Shen ${ }^{2}$ \\ 1 School of Economics and Management, North China Electric Power University, Beijing 102206, China; \\ 2 State Grid Zhejiang Electric Power Company Hangzhou Power Supply Company, Hangzhou 310000, China; \\ * Correspondence: kg1995538530@163.com; Tel:13124719766
}

\begin{abstract}
:
Risk of corporate social responsibility (CSR) refers to the possibility and consequences of the potential lack of CSR, which will cause damage and loss to society and enterprises. Hence, scientific evaluation of CSR risk is conducive to enterprises to take timely risk response measures and reduce potential risk factors. In order to fully reflect the CSR risk, a comprehensive risk evaluation index system is established from four dimensions of corporate stakeholders, law, environment and charity. In addition, hesitant fuzzy language is used to describe the CSR risk information, so as to reflect the uncertainty in the process of risk judgment. Considering the complexity of the CSR concept and the possible discreteness of risk results, the hesitant fuzzy language-cloud model is established to evaluate CSR risk level. Finally, utilizing China Huaneng Group as a case to apply the CSR risk evaluation model, it is found that the overall CSR risk level of Huaneng is relatively low. Through further comparative and hierarchical analysis, it is found that the CSR risk of community stakeholders is relatively high, and the CSR risk of legal, environmental and charitable is relatively balanced.
\end{abstract}

Key words: CSR; risk assessment; hesitation fuzzy language; cloud model

\section{Introduction}

As an independent economic entity, enterprises realize the company's profit-making goal by optimizing the allocation of resources. However, if enterprises only blindly pursue economic interests and ignore their social responsibilities, it will inevitably aggravate the relationship between enterprises and society (Dima et al. 2007). In recent years, the lack of corporate social responsibility (CSR) has caused many problems such as food safety employee protection, and environmental pollution. When the company does not actively undertake CSR, once a social responsibility accident occurs, it will cause huge economic losses and trust crisis, and may lead to the bankruptcy of the company (Kuo et al. 2020). Therefore, it is particularly important to effectively evaluate CSR risk, and improve the capability of CSR risk management and control. 
CSR risk is a derivative concept of CSR. In a broad sense, CSR includes the responsibility of the company to all stakeholders, and is a unify of philosophical concepts, behavioral processes, and fulfillment consequences (Carroll 1999). The definition of risk can be understood as the possibility of potential undesirable situations, and a high risk is a high possibility of unexpected situations. Therefore, CSR risk refers to the risks that may occur in the business process related to the content of CSR. The scientific evaluation of CSR risk is conducive to timely control the potential risk factors of CSR and promote the sustainable green development of enterprises.

The academic evaluation of CSR mainly includes triple bottom line mode, stakeholders evaluation model and Carroll's pyramid model. Richardson andHenriques (2004) proposed that enterprises should perform basic economic, social and environmental responsibilities. The Global Reporting Initiative (GRI) and the Dow Jones Sustainability Index (DJSI) have constructed the social responsibility evaluation index system based on the theory of triple bottom line theory (Halkos \&Nomikos 2021, López \&Rodriguez 2007). Scholars represented by Freeman(R 1984) put forward the stakeholders theory which pointed out the specific object of CSR. According to the stakeholders, CSR can be divided into different stakeholders social responsibility. Clarkson (1998) selected typical enterprise stakeholder to build an index system to evaluate CSR. These corporate stakeholder indicators include employees, shareholders and suppliers, and each stakeholder includes corresponding secondary indicators. Carroll (1979) divided CSR into economic responsibility, legal responsibility, ethical responsibility and charitable responsibility, and constructed the pyramid model of CSR evaluation. However, it also has the following shortcomings: firstly, the meaning of legal responsibility is confused, corporate legal responsibility requires enterprises to make profits and pay taxes, it can be said that economic responsibility is covered in the scope of legal responsibility; secondly, there is no essential difference between ethical responsibility and charitable responsibility in legal sense, it can be considered that voluntary responsibility is a higher level of charitable responsibility.

Due to the lack of research on CSR risk evaluation in the existing literatures, the research on CSR evaluation can provide a research basis for CSR risk evaluation research. With regard to CSR assessment, the existing literatures mainly focus on the evaluation index and model methods of CSR (Nikolaou et al. 2013, Rajak \&Vinodh 2015, Valiente et al. 2012). However, the current studies lack a comprehensive index system suitable for CSR risk evaluation. In addition, the existing CSR assessment models fail to fully consider the complexity of CSR concepts, the uncertainty of CSR risks, and the dynamics and possible dispersion in the process of risk analysis. In order to overcome the above difficulties, this paper firstly constructs an evaluation index system that takes into account corporate stakeholders, legal, environmental and 
charity levels of CSR. Secondly, the CSR risk evaluation model based on hesitant fuzzy language-cloud model is firstly proposed, which adopts hesitant fuzzy language to describe risk assessment information and applies cloud model to quantify the fuzzy language and determine the risk level, which fully expresses the uncertainty and dispersion in the risk assessment process while ensuring the complete conversion of decision-makers' fuzzy information. Finally, the paper empirically analyzes the CSR risks of China Huaneng Group and innovatively conducts a comprehensive comparative analysis of CSR risk based on the perspective of stakeholders, legal, environment and charity levels. Research conclusions have guiding significance for the scientific regulation of CSR policies and improving the capacity of CSR risk management.

The main contribution of this paper can be summarized as following points: i) This article studies the management and control of CSR from a risk perspective, which supplements the research field of the CSR and risk management. ii) A CSR risk evaluation index which covers the stakeholders' requirements and CSR risk level is established in this paper for the first time. iii) Considering the uncertain environment of CSR risk evaluation, hesitant fuzzy language-cloud model decision framework is established. iv) This article analyzes the CSR risk of Huaneng Group through comparative analysis and hierarchical analysis method, which can be widely used in CSR risk evaluation and a theoretical supplement of the research on this aspect.

The rest of the paper is organized as follows: Section 2 summarizes and analyzes the related literatures; Section 3 constructs the CSR risk evaluation model; the case study and relevant discussion are introduced in Section 4; and Section 5 outlines the conclusion.

\section{Literature review}

\subsection{Evaluation methods of CSR risk}

CSR risk emphasizes the estimate of risk uncertainty compared with CSR, but at the same time, their concepts are closely related. The assessment of CSR risk needs to be based on the scientific evaluation of CSR. At present, the academic research on CSR measurement methods has a certain foundation, which provides a certain research basis for the development of CSR evaluation. With regard to the measurement approaches of CSR, the main methods adopted by academia include reputation index method, index analysis method and content analysis method (Galant et al. 2017). Reputation index method mainly measures CSR in the form of questionnaires; this method is rarely used in academic research because it depends on the quality of the questionnaires and the cognition of the respondents (Chojnacka \&Wiśniewska 2016). The index analysis method, which is usually based on information released by third-party institutions, has gained wide application in the field of CSR empirical research, but the results of the index analysis method rely on 
the third-party social assessment institutions, which cannot further meet the needs of CSR risk analysis (Baek \&Kim 2021). Content analysis method collects relevant CSR information disclosed by enterprises on the basis of establishing certain CSR evaluation criteria and scores them to obtain CSR evaluation results, and it is widely used in CSR evaluation model research (Liao et al. 2018).

On the basis of content analysis method, Li et al. (2021) combined analytic hierarchy process (AHP) and fuzzy comprehensive evaluation method to evaluate the performance of CSR. Baofeng (2020) evaluated CSR based on the information disclosed in CSR report and annual report, and improve the robustness of CSR evaluation results by combining different single empowerment methods. Govindan et al. (2014) designed the CSR analysis framework of Indian mining enterprises through fuzzy decision-making methods from the perspective of multi-stakeholders. Karaman andAkman (2018) applied hierarchical analysis (AHP) to evaluate and measure CSR project criteria among multiple alternatives, and assessing the relative importance of relevant factors by means of expert scoring to obtain the assessed value of CSR commitment. Meng et al. (2018) established a cloud model-based CSR evaluation model to score the cloud feature values of evaluated objects through expert discussions, but the method only considers the ambiguity of evaluation objects in decision making without considering the uncertainty of decision makers in the evaluation process.

Research literatures on CSR risk assessment are relatively scarce. Combined with the real option theory, Husted (2005) analyzed the impact of CSR on corporate risk management, and proposes that CSR is conducive to reducing the prior downside risk of enterprises. From the perspective of sustainable supply chain management, Jian et al. (2014) studied the CSR risk of China's automobile industry, and determines the risk level through the standard deviation between the risk value and the expected value of each index. This method reflects the risk through standard deviation, and considers the discrete type of risk, but it is not conducive to reflect the risk level of each index, and cannot reflect the hesitation of decision makers. The paper intends to establish a CSR risk evaluation model with universal applicability, and considers the hesitant ambiguity in all decision-making processes to make the evaluation results more consistent with the real situation of enterprises.

\subsection{Application of hesitant fuzzy language and cloud model in CSR risk evaluation}

In the actual evaluation process, considering the complexity of CSR concepts and the inherent fuzziness of human thinking, only utilizing quantitative variables cannot satisfy the requirements for accurate evaluation of issues, so qualitative language is required for preference descriptions. Therefore, hesitant fuzzy sets such as "high", "slightly high", "low" and "slightly low" are often used to express decision-makers' risk evaluation information (Liao et al. 2017). Linguistic hesitant fuzzy set (LHFS) can reflect the decision-makers' hesitation between multiple 
linguistic terms and can give the corresponding degree of hesitation according to their own preferences. Liao et al. (2014) studied the distance degree measure for different LHFS languages in multi-attribute decision-making process and demonstrated its feasibility and superiority. The concept of fuzzy language has gained continuous development since it was proposed, such as triangular fuzzy numbers (Vahdani et al. 2011), trapezoidal fuzzy numbers (Abbasbandy \&Hajjari 2009) and intuitionistic fuzzy sets (Zhou \&Gao 2020). These fuzzy languages describe the uncertainty of evaluated objects from different perspectives and facilitate the expression of decision-makers' judgments, but the above methods cannot avoid the randomness in the evaluation process. After giving the risk linguistic values, how to convert the linguistic values into calculable values and without losing the information of the data is one of the key issues in risk evaluation. To solve the above problems, the paper introduces the cloud model into the CSR risk evaluation and combines it with hesitant fuzzy language to jointly achieve the description and evaluation of CSR risks.

The existing methods used on risk evaluation mainly include comprehensive evaluation method ( $\mathrm{Li}$ et al. 2018), grey evaluation method (Cui et al. 2019), cloud model (Hu-Chen et al. 2018). In the evaluation process, when there is a large complementarity between the advantages and disadvantages of the indicators, the evaluation results of fuzzy evaluation method and grey fuzzy evaluation method tend to mask the true risk level of the evaluation object, and cannot express the discrete evaluation process in a fuzzy environment (Chuanxi et al. 2016). As a method of converting quantitative and qualitative data, the cloud model successfully describes the uncertainty and dispersion of evaluation indicators through three numerical characteristics to present all possible information of evaluation objects in a comprehensive and systematic way, and has been widely used in performance and risk evaluation in different fields (Hui et al. 2015, Wu et al. 2018). Therefore, in order to fully express the hesitation, fuzziness and uncertainty of decision-makers, and to make the risk evaluation process more realistic, the paper establishes a CSR risk evaluation model based on hesitant fuzzy language-cloud model.

\section{CSR risk evaluation model}

\subsection{Establishment of CSR risk index system}

In order to promptly identify potential CSR risk events that may affect the company, first of all, it is necessary to establish and improve the measurement standards (indicators) of CSR risk.

\subsubsection{Criterion-level indicators}

The establishment of CSR risk assessment index system needs to be based on the analysis of the content and influencing factors of CSR. The broad concept of CSR believes that CSR scope includes the integration of CSR fulfillment, process and consequences. In terms of service objects, CSR is the responsibility to corporate 
stakeholders; and in terms of corporate subjective initiative, CSR includes legal, environmental, and philanthropic aspects. The CSR risk can be understood as risk factors related to CSR that may appear during the implementation of corporate strategies. Therefore, CSR risk has a certain corresponding relationship with CSR in scope, and CSR risk factors are consistent with CSR in content. The corresponding relationship between CSR and CSR risk is shown in Fig 1.

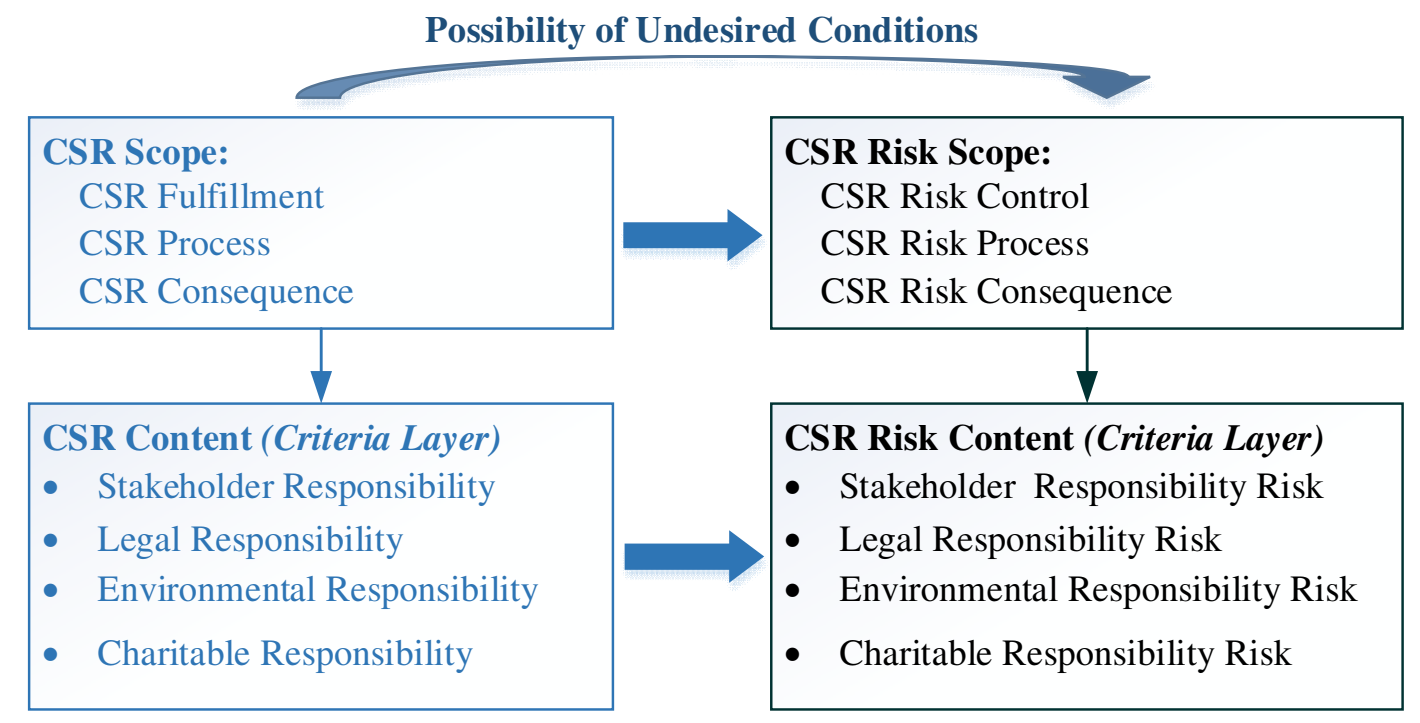

Fig 1. The relationship between CSR and CSR risk

Regarding the establishment of CSR risk criterion-level indicators. The theory of stakeholders puts forward the objects of CSR, so the corporate CSR risks are also related to these stakeholders (Akremi et al. 2018, Yang et al. 2018). There is a two-way relationship between enterprises and stakeholders, and stakeholder-risk expounds the dual-centered CSR idea of enterprises and stakeholders. Therefore, this article regards corporate stakeholders as a criterion-level indicator of CSR risk, which can fully reflect the risks of corporate stakeholders. In addition, considering that it is difficult to attribute CSR such as legal responsibility, environmental responsibility to a specific stakeholder, this paper also establishes criterion-level indicators based on corporate legal responsibility, environmental responsibility and charitable responsibility, so as to comprehensively reflect CSR risk (Farooq et al. 2021). The initiative of corporate is improving from corporate legal responsibility, environmental responsibility to charitable responsibility, and enterprises are required to improve environmental responsibility and charitable responsibility on the premise of satisfying legal responsibility (Masud et al. 2019). In addition, it is noteworthy that the content of legal responsibility covers the environmental obligations required by law, so the environmental responsibility risk in the paper refers to the environmental responsibility that enterprises proactively undertake in excess of their legal responsibilities.

\subsubsection{Second-level indicators}

On the basis of the criterion-level indicators, specific second-level indicators which are associated with the above four criterion-level indicators are identified via 
the following approaches: i) comply with the standards of ISO social responsibility guidelines (ISO26000), the Global Reporting Initiative (GRI) sustainability report guideline (G4) and other authoritative reports (Tsalis T.A 2020). ii) comply with the principle of typical indicators high frequency of authoritative institutions and related literatures (Tseng et al. 2017, Zhao et al. 2012). Finally, the CSR risk evaluation index system constructed in the paper is shown in Table 1.

1) Stakeholders responsibility risk

Shareholder (C11): The shareholder risk is mainly due to the poor management of the enterprise, which cannot bring the expected equity returns and affect the interests of shareholders.

Creditor (C12): The creditor risk refers to the risk that the company cannot repay the creditor's principal and interest due to the shortage of corporate funds.

Consumer (C13): The consumer risks mainly come from the quality of products and services of enterprises, and the unqualified output of enterprises leads to the infringement of consumer interests.

Employee (C14): The employee risk are mainly the risks of work-related injuries, occupational diseases, and uncertain income, as well as the possible risks of being dismissed in the future.

Manager (C15): The manager risk comes from the risk that corporate executives fail to achieve capacity enhancement and career development, and affect future career planning.

Government (C16): The government risk lies in the lack of CSR performance, which leads to the social instability, and at the same time, enterprises are more vulnerable to the punishment of the government.

Competitor (C17): The competitor risk lies in the economic losses of both parties caused by dishonesty, malicious competition, dishonesty, etc. when the company interacts with other business partners.

Community (C18): Community risk is reflected in the potential risk of damaging the interests of the community due to the insufficient performance in community environment and sanitation.

2) Legal responsibility risk

National laws (C21): National regulations are the basic responsibilities that enterprises need to perform, and if enterprises fail to perform their legal responsibilities, they will be punished by law.

International conventions (C22): International conventions include ISO, GRI and other industry conventions, and failure to implement international conventions will affect the product service quality and reputation of enterprises.

Industry and internal regulations (C23): Industry norms and internal control mechanisms vary with different enterprise characteristics, and failure to comply with industry and internal norms will lead to increase of corporate risk.

3) Environmental responsibility risk

Resource conservation (C31): The failure of enterprises to save resources will lead to a waste of environmental resources and at the same time increase the production costs of enterprises. 
Environment protection (C32): The lack of environmental protection of enterprises will lead to the deterioration of the ecological environment, and increase the possibility of environmental punishment by the government.

4) Charitable responsibility risk

Social donation (C41): The social donation is a voluntary CSR behavior of enterprises, and social donation is conducive to improving the reputation of enterprises, but it will also increase the cost of enterprises.

Poverty alleviation (C42): Enterprises, especially state-owned enterprises, have the responsibility of poverty alleviation, and if enterprises do not actively carry out poverty alleviation, it may be detrimental to their relationship with the government.

Provide public employment (C43): Enterprises need to provide employment for society, and if enterprises perform poorly in providing employment, it may lead to pressure from the government and the public.

Public education (C44): The provision of public education support by enterprises is conducive to improving citizenship and corporate reputation, and the poor performance in public education may lead to public censure.

Table 1. CSR risk evaluation index system

\begin{tabular}{ccc}
\hline Criterion-level indicators & Abbreviation & Second-level indicators \\
\hline \multirow{5}{*}{ Stakeholders responsibility } & $\mathrm{C} 11$ & Shareholder \\
& $\mathrm{C} 12$ & Creditor \\
& $\mathrm{C} 13$ & Consumer \\
& $\mathrm{C} 14$ & Employee \\
& $\mathrm{C} 15$ & Manager \\
& $\mathrm{C} 16$ & Government \\
& $\mathrm{C} 17$ & Competitor \\
& $\mathrm{C} 18$ & Community \\
\hline \multirow{4}{*}{ Legal responsibility } & $\mathrm{C} 21$ & Compliance with national laws \\
& $\mathrm{C} 22$ & Compliance with international conventions \\
& $\mathrm{C} 23$ & Compliance with industry and internal regulations \\
\hline \multirow{2}{*}{ Environmental responsibility } & $\mathrm{C} 31$ & Resource conservation \\
& $\mathrm{C} 32$ & Environment protection \\
\hline \multirow{2}{*}{ Charitable responsibility } & $\mathrm{C} 41$ & Social donation \\
& $\mathrm{C} 42$ & Pupport poverty alleviation \\
& $\mathrm{C} 43$ & Provide public employment \\
& $\mathrm{C} 44$ & Support public education \\
\hline
\end{tabular}

3.2 Fuzzy hesitation language-cloud model

Risk measurement includes the collection of risk information and the determination of risk levels, and is an important part of risk management, which provides a basis for risk control. This paper identifies and evaluates the risk information through hesitation fuzzy language and cloud model, which can adapt to the uncertain environment of risk decision-making.

3.2.1 Linguistic Hesitant Fuzzy Set 
The uncertainty in the CSR risk evaluation process requires the use of qualitative linguistic information for preference descriptions. Linguistic term sets can help decision-makers evaluate natural language in an environment with limited human cognition. For example, $\begin{aligned} & s_{0}=\text { extremely poor, } s_{1}=\text { very poor, } s_{3}=\text { poor, } s_{4}=\text { medium, } \\ & s_{5}=\text { good, } s_{6}=\text { very good, } s_{7}=\text { extremely good }\end{aligned}$ is a linguistic term set containing seven linguistic scales. The linguistic hesitant fuzzy set (LHFS) is a set of linguistic terms to which the hesitant degree of the decision-makers is added, and the LHFS can be denoted as $\alpha=\left\{s_{\theta}, \operatorname{lh}\left(s_{\theta}\right)\right\}$, where $s_{\theta} \in S$ is the set of linguistic terms and $\operatorname{lh}\left(s_{\theta}\right)=\left\{r_{1}, r_{2}, \ldots, r_{m_{i}}\right\}$ denotes several possible affiliations to the set of linguistic terms $s_{\theta}$.

For $S=\left\{\begin{array}{l}s_{0}=\text { extremely high, } s_{1}=\text { high, } s_{2}=\text { slightly high, } \\ s_{3}=\text { medium, } s_{4}=\text { slightly low, } s_{5}=\text { low, } s_{6}=\text { very low }\end{array}\right\}$, during the evaluation process, the expert committee may give a "slightly high" affiliation of 0.6 and a "medium" affiliation of 0.3 , but may hesitate to give a "high" value of 0.2 or 0.3 . In this case, the evaluation value can be expressed as $\alpha=\left\{\left(s_{1}, 0.2,0.3\right),\left(s_{2}, 0.6\right),\left(s_{3}, 0.3\right)\right\}$.

\subsubsection{Cloud model}

Uncertainty is mainly manifested in two different aspects: randomness and vagueness (Deng \&Jiang 2019). Randomness is caused by the causality of events, which are probabilities in probability theory; while fuzziness implies the lack of clarity of boundaries. The cloud model reflects the uncertainty and dispersion of objects through expectation, entropy, and super entropy (Wang et al. 2015). Expectation $E x$ reflects the central value of the cloud model; entropy $E n$ is a measure of cloud model fuzziness, and the larger the entropy is, the more fuzzy the object is; super entropy $H e$ can be understood as the entropy of En, reflecting the dispersion degree of cloud drops, and the larger the super entropy is, the thicker the cloud is.

Assuming two cloud models $X\left(E_{x_{1}}, E_{n_{1}}, H_{e_{1}}\right)$ and $Y\left(E_{x_{2}}, E_{n_{2}}, H_{e_{2}}\right)$, the basic operations between cloud models $X$ and $Y$ are referenced in this paper (Hu-Chen et al. 2018).

$$
\begin{aligned}
& X+Y=\left(E_{x_{1}}+E_{x_{2}}, \sqrt{{E_{n_{1}}{ }^{2}+E_{n_{2}}{ }^{2}}_{1}}, \sqrt{{H_{e_{1}}{ }^{2}+H_{e_{2}}{ }^{2}}^{2}}\right. \\
& X-Y=\left(E_{x_{1}}-E_{x_{2}}, \sqrt{{E_{n_{1}}{ }^{2}+E_{n_{2}}{ }^{2}}^{2}}, \sqrt{{H_{e_{1}}{ }^{2}+H_{e_{2}}{ }^{2}}^{2}}\right)
\end{aligned}
$$




$$
\begin{gathered}
X \times Y=\left(E_{x_{1}} E_{x_{2}}, \sqrt{\left(E_{n_{1}} E_{x_{2}}\right)^{2}+\left(E_{x_{1}} E_{n_{2}}\right)^{2}}, \sqrt{\left(H_{e_{1}} E_{x_{2}}\right)^{2}+\left(E_{x_{1}} H_{e_{2}}\right)^{2}}\right) \\
X \div Y=\left(\frac{E_{x_{1}}}{E_{x_{2}}},\left|\frac{E_{x_{1}}}{E_{x_{2}}}\right| \times \sqrt{\left(\frac{E_{n_{1}}}{E_{x_{1}}}\right)^{2}+\left(\frac{E_{n_{2}}}{E_{x_{2}}}\right)^{2}}, \mid \frac{E_{x_{1}}}{E_{x_{2}}} \times \sqrt{\left(\frac{H_{e_{1}}}{E_{x_{1}}}\right)^{2}+\left(\frac{H_{e_{2}}}{E_{x_{2}}}\right)^{2}}\right) \\
X^{m}=\left(E_{x_{1}}, \sqrt{m} E_{x_{1}}{ }^{m-1} E_{n_{1}}, \sqrt{m} E_{x_{1}}{ }^{m-1} H e_{1}\right) \\
m X=\left(m E_{x_{1}}, \sqrt{m} E_{n_{1}}, \sqrt{m} H_{e_{1}}\right)
\end{gathered}
$$

For the evaluation results of the second-level indicators, the aggregated cloud model can be obtained by combining the weights of the indicators, and the aggregation process is as follows:

$$
\begin{gathered}
E x=\frac{E x_{1} \omega_{1}+E x_{2} \omega_{2}+\ldots+E x_{n} \omega_{n}}{\sum_{i=1}^{m} \omega_{i}} \\
E n=\frac{\omega_{1}^{2}}{\sum_{i=1}^{m} \omega_{i}^{2}} E n_{1}+\frac{\omega_{2}^{2}}{\sum_{i=1}^{m} \omega_{i}^{2}} E n_{2}+\ldots+\frac{\omega_{m}^{2}}{\sum_{i=1}^{m} \omega_{i}^{2}} E n_{m} \\
H e=\frac{\omega_{1}^{2}}{\sum_{i=1}^{m} \omega_{i}^{2}} H e_{1}+\frac{\omega_{2}^{2}}{\sum_{i=1}^{m} \omega_{i}^{2}} H e_{2}+\ldots+\frac{\omega_{m}^{2}}{\sum_{i=1}^{m} \omega_{i}^{2}} H e_{m}
\end{gathered}
$$

To ensure the accuracy and comprehensiveness of the risk evaluation, seven standard cloud models based on golden section method are employed to describe the risk level of each indicator of the evaluation object (Chuanxi et al. 2016). The eigenvalues of the seven standard clouds are shown in Table 2.

Table 2. Standard cloud model eigenvalues

\begin{tabular}{ccccc}
\hline Fuzzy language & Abbreviation & Ex & En & He \\
\hline Very high risk & $\mathrm{s} 0$ & 0 & 0.833 & 0.424 \\
High risk & $\mathrm{s} 1$ & 2.5 & 0.515 & 0.262 \\
Slightly high risk & $\mathrm{s} 2$ & 4.045 & 0.318 & 0.162 \\
Medium risk & $\mathrm{s} 3$ & 5 & 0.197 & 0.100 \\
Slightly low risk & $\mathrm{s} 4$ & 5.955 & 0.318 & 0.162 \\
Low risk & $\mathrm{s} 5$ & 7.5 & 0.515 & 0.262 \\
Very low risk & $\mathrm{s} 6$ & 10 & 0.833 & 0.424 \\
\hline
\end{tabular}

\subsubsection{Conversion of LHFS into integrated clouds}

Assume that $S=\left\{s_{0}, s_{1}, \ldots, s_{t-1}\right\}$ is a language set and $t$ is an odd number. A valid range $\left[X_{\min }, X_{\max }\right]$ is given by experts. When converting a linguistic term $s_{\theta}$ 
into a corresponding cloud $A_{\theta}\left(E x_{\theta}, E n_{\theta}, H e_{\theta}\right)$, the corresponding language fuzzy set $a$ is transformed into an integrated cloud $A_{\alpha}\left(E x_{\alpha}, E n_{\alpha}, H e_{\alpha}\right)$. The specific transformation formula for the three numerical features of the integrated cloud is as follows.

$$
\begin{gathered}
E x_{\alpha}=\sum_{\theta \in \operatorname{index}(\alpha)}\left(\left(\frac{\sum_{r \in \operatorname{lh}\left(s_{\theta}\right)} r}{\left|\operatorname{lh}\left(s_{\theta}\right)\right|} / \sum_{\theta \in \operatorname{index}(\alpha)} \frac{\sum_{r \in \operatorname{lh}\left(s_{\theta}\right)} r}{\left|\operatorname{lh}\left(s_{\theta}\right)\right|}\right) E x_{\theta}\right) \\
E n_{\alpha}=\sum_{\theta \in \operatorname{index}(\alpha)}\left(\left(\frac{\sum_{r \in \operatorname{ll}\left(s_{\theta}\right)} r}{\left|\operatorname{lh}\left(s_{\theta}\right)\right|} / \sum_{\theta \in \operatorname{index}(\alpha)} \frac{\sum_{r \in \operatorname{lh}\left(s_{\theta}\right)} r}{\left|\operatorname{lh}\left(s_{\theta}\right)\right|}\right) E x_{\theta} E n_{\theta}\right) / E x_{\alpha} \\
H e_{\alpha}=\sqrt{\sum_{\theta \in \operatorname{index}(\alpha)}\left(H e_{\theta}\right)^{2}}
\end{gathered}
$$

Where $\left|\operatorname{lh}\left(s_{\theta}\right)\right|$ represents the total number of affiliations of $\operatorname{lh}\left(s_{\theta}\right)$ with respect to the hesitant fuzzy language $s_{\theta}$, and index $(\alpha)=\left\{\theta \mid\left(s_{\theta}, \operatorname{lh}\left(s_{\theta}\right)\right) \in \alpha, \operatorname{lh}\left(s_{\theta}\right) \neq\{0\}\right\}$ when $s_{\theta} \in S$.

\subsubsection{Cloud model closeness}

The similarity of cloud models includes shape similarity and distance similarity. The shape similarity of the cloud model is a measure of its uncertainty, which is reflected by the difference of sum of squares of En and $\mathrm{He}$. The closer the uncertainty of two cloud models is, the greater the shape similarity of the two cloud models, that is, the greater $\operatorname{Sim}_{s}$. Such as $A_{i}\left(E x_{i}, E n_{i}, H e_{i}\right)$ and $A_{j}\left(E x_{j}, E n_{j}, H e_{j}\right)$, the shape similarity of the cloud models can be calculated by the following equation.

$$
\operatorname{Sim}_{s}\left(A_{i}, A_{j}\right)=\sqrt{\frac{\min \left(D\left(A_{i}\right), D\left(A_{j}\right)\right)}{\max \left(D\left(A_{i}\right), D\left(A_{j}\right)\right)}}
$$

where $D(A)=E n^{2}+H e^{2}$.

The distance similarity of cloud models is reflected by the difference between the expectation of two cloud models, and the closer the distance between cloud models, the larger the distance similarity value, that is, the larger $\operatorname{Sim}_{d}$. Suppose two cloud models $A_{i}\left(E x_{i}, E n_{i}, H e_{i}\right)$ and $A_{j}\left(E x_{j}, E n_{j}, H e_{j}\right), d$ is the distance between the two 
clouds, $d=\left|E x_{i}-E x_{j}\right|$. The distance between two cloud models can be obtained by the following equation:

$$
\operatorname{Sim}_{d}=\frac{S(d)}{S(0)}
$$

where $S(d)$ is the overlap region of the expected curves of the two cloud models, and $S(0)$ is the overlap region when $d=0$.

Generally, after the ratio of the entropy of the two clouds $k$ is determined, there is a certain correspondence between $\operatorname{Sim}_{d}$ and the relative distance $\theta$ of the two cloud expectations, that is, satisfying the functional relationship $\operatorname{Sim}_{d}=a \times \exp \left(-((\theta-b) / c)^{2}\right)$ which has been proved by Wang et al. (2017). The coefficients of the fitting function are shown in Table 3.

Table 3. Coefficients of cloud model fitting function

\begin{tabular}{cccccc}
\hline$\theta_{0}$ & $k$ & $a$ & $b$ & $c$ & Adj $R-s q$ \\
\hline 0.0 & 1.000 & 1.42 & -0.3142 & 0.527 & 1.0000 \\
0.1 & 1.222 & 1.256 & -0.2038 & 0.4772 & 0.9995 \\
0.2 & 1.500 & 1.088 & -0.08523 & 0.4213 & 0.9990 \\
0.3 & 1.857 & 1.026 & -0.01631 & 0.393 & 0.9992 \\
0.4 & 2.333 & 1.007 & 0.02322 & 0.3859 & 0.9997 \\
0.5 & 3.000 & 1.002 & 0.04800 & 0.3914 & 0.9999 \\
0.6 & 4.000 & 1.001 & 0.06496 & 0.4043 & 0.9998 \\
0.7 & 5.667 & 1.002 & 0.07731 & 0.4218 & 0.9996 \\
0.8 & 9.000 & 1.002 & 0.08654 & 0.4423 & 0.9994 \\
0.9 & 19.000 & 1.003 & 0.09325 & 0.4654 & 0.9992 \\
1 & 20000 & 1.003 & 0.09759 & 0.4911 & 0.9993 \\
\hline
\end{tabular}

Where $\theta=\left|E x_{i}-E x_{j}\right| /\left(3 \times\left(E n_{i}+E n_{j}\right)\right), \theta_{0}=(k-1) /(k+1)$ and $k=\frac{E n_{1}}{E n_{2}}$.

Criterion 1: When $\theta \in[0,1)$, then $\operatorname{Sim}_{d}>0$;

Criterion 2: When $\theta \in[1,+\infty)$, then $\operatorname{Sim}_{d}=0$;

Finally, the paper takes into account the shape dimension and distance dimension for the calculation of cloud model closeness. The cloud model closeness $\operatorname{Sim}_{c}$ based on shape and distance can be determined as follows:

$$
\operatorname{Sim}_{c}=\operatorname{Sim}_{d} \times \operatorname{Sim}_{s}
$$


Finally, the overall CSR risk management processes for enterprise can be clearly showed as Fig 2.

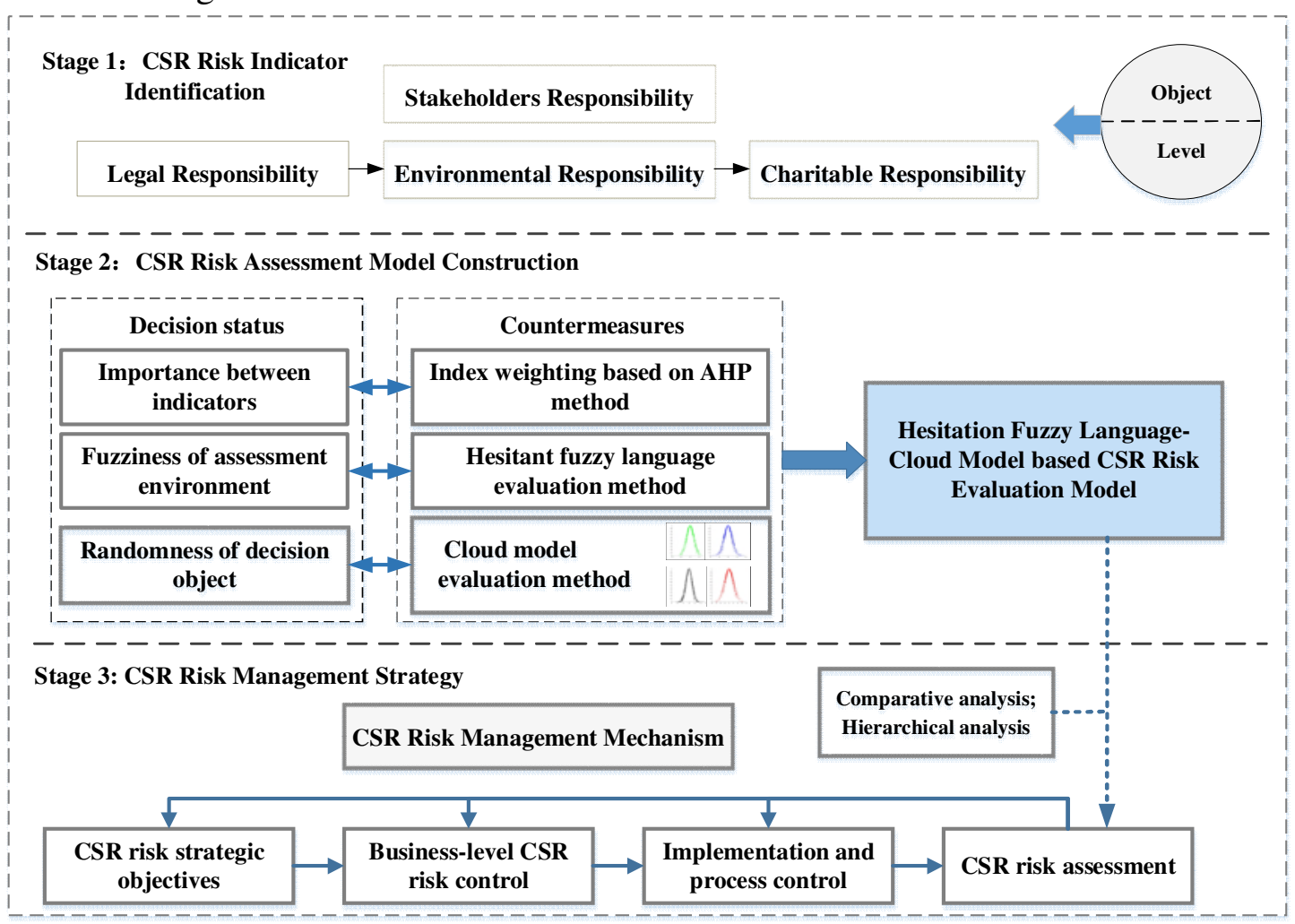

Fig 2. CSR risk management logic diagram

\section{An empirical case analysis}

\subsection{Sample selection and data sources}

This paper takes China Huaneng Group CO., Ltd. (hereinafter referred to as Huaneng Group) as a case to evaluate its CSR risk level from 2010 to 2018. The reasons for choosing this company as a case are as follows: firstly, there are several listed companies under Huaneng Group, which provides a wealth of data foundation for risk analysis and ensure the accuracy of risk values; secondly, Huaneng Group, as a leading enterprise in China energy industry, is more likely to receive attention from social media and the government; finally, the research team's research foundation on Huaneng Group is conducive to more accurate risk assessment.

The main CSR risk assessment data in the paper are from the sustainability reports disclosed by Huaneng Group, and employ China Stock Market \& Accounting Research Database (CSMAR), China litigation and arbitration research database, violation treatment research database, ISO9001 quality management system, international social responsibility standard SA8000, and GRI "Sustainability Reporting Guide" as the supporting judgment materials for CSR risk evaluation.

\subsection{CSR index weight assignment and risk evaluation}

The assignment of index weight in this paper applies the AHP method, which determines the weight by judging the relative importance of the discriminated index. 
This method systematizes and quantifies the human thinking process, and is suitable for the weight setting of the multi-index system in this article (Cl \&Gang 2020). The judgment of index importance is determined by expert discussion. The selected experts are specialized in the fields of CSR and risk management, besides all the selected experts have a deep research experience on Huaneng Group. Finally, the index weight can be determined after a set of calculation of the comparison matrix via MATLAB software. The weight results of each indicator are shown in Table 4.

Table 4. CSR index weight of Huaneng Group

\begin{tabular}{ccc}
\hline Indicators & Level 1 Indicators & Level 2 Indicators \\
\hline C11 12 & & 0.045 \\
C12 13 & 0.045 \\
C13 & & 0.087 \\
C14 15 & 0.4673 & 0.087 \\
C15 & 0.045 \\
C16 & & 0.045 \\
C17 & & 0.025 \\
C18 & & 0.087 \\
C21 & & 0.038 \\
C22 & & 0.019 \\
C23 & 0.0954 & 0.038 \\
\hline C31 & & 0.139 \\
C32 & \multirow{2}{*}{0.2772} & 0.139 \\
C41 & & 0.056 \\
C42 & & 0.056 \\
C43 & & 0.03 \\
C44 & 0.1601 & 0.017 \\
\hline
\end{tabular}

Considering that experts may have a certain degree of uncertainty and hesitation in the process of risk judgment, as well as the possibility of inconsistencies in the discussion results of the expert group. Therefore, the expert group utilizes LHFS to describe the risk value of each indicator, and then aggregates and ranks it through cloud model. In this paper, the linguistic estimated value of the expert group on Huaneng Group CSR risk in 2018 are presented in Table 4. Taking C11 as an example, the expert group has a hesitation degree of 0.3 for $\mathrm{s} 3$ and a hesitation degree of 0.2 for s4. Applying formulas (10) to (12), the hesitant fuzzy language of expert scoring is converted into the characteristic values of the comprehensive cloud. After that, formulas (10-12) are applied to convert the hesitant fuzzy language in Table 5 into the eigenvalues of the integrated cloud.

Table 5. Linguistic estimated value of Huaneng Group in 2018

\begin{tabular}{clc}
\hline Indicators & \multicolumn{1}{c}{ Experts' judgment of CSR risk } \\
\hline C11 & Medium $(s 3)=0.3$ & Slightly low $(\mathrm{s} 4)=0.2$ \\
C12 & Medium $(\mathrm{s} 3)=0.4$ \\
C13 & Medium $(\mathrm{s} 3)=0.3$
\end{tabular}




\begin{tabular}{lll} 
C14 & Medium(s3) $=0.3$ & Slightly low(s4) $=0.3$ \\
C15 & Medium(s3) $=0.3$ & \\
C16 & Medium(s3) $=0.3$ & \\
C17 & Slightly high(s2) $=0.2$ & Medium(s3) $=0.2$ \\
C18 & Medium(s3) $=0.2$ & \\
C21 & Low(s5) $=0.6$ & \\
C22 & Low(s5) $=0.6$ & \\
C23 & Low s5 $=0.3$ & \\
C31 & Medium(s3) $=0.2$ & Slightly low(s4) $=0.3$ \\
C32 & Medium(s3) $=0.2$ & Slightly low(s4) $=0.3$ \\
C41 & Slightly low(s4)=0.2 & Low(s5) $=0.4$ \\
C42 & Medium(s3) $=0.3$ & Slightly low(s4) $=0.4$ \\
C43 & Medium(s3) $=0.3$ & Slightly low(s4) $=0.1$ \\
C44 & Medium(s3) $=0.2$ & \\
\hline
\end{tabular}

\subsection{CSR risk evaluation results}

In order to accurately determine which risk level the integrated cloud of expert score results belongs to, the closeness of the integrated cloud to each standard cloud model is calculated using formulas (7-9), which takes into account the shape similarity as well as the distance similarity. The closeness between the Huaneng Group's 2010-2018 integrated cloud and the seven standard cloud are shown in Table 6. Observing the closeness of Huaneng Group CSR risks to the standard cloud model, it is found that the closeness to the standard cloud s0, s1 and s6 are all 0 , and the level of closeness to the standard cloud s2 and s5 is very low. It indicates that the risk level of Huaneng Group evaluated by the expert group is relatively convergent; the closeness to very high risk and high risk is 0 , which indicates that the possibility of serious CSR accidents of Huaneng Group is extremely low.

However, the closeness of Huaneng Group CSR risk level close to s6 is 0, which indicates that although Huaneng Group has a low risk level in general, it still cannot achieve the capacity of preventing the occurrence of CSR risk accidents. The maximum closeness of Huaneng Group CSR risk level from 2010 to 2018 is subordinate to s4, except for 2011 which is subordinate to s3. From a comprehensive perspective, Huaneng Group has a good CSR risk management and control mechanism.

Table 6. The closeness between CSR risk of Huaneng Group and standard cloud model

\begin{tabular}{cccccccc}
\hline Year & $\begin{array}{c}\text { Very high } \\
(\mathrm{s} 0)\end{array}$ & $\begin{array}{c}\text { High } \\
(\mathrm{s} 1)\end{array}$ & $\begin{array}{c}\text { Slightly high } \\
(\mathrm{s} 2)\end{array}$ & $\begin{array}{c}\text { Medium } \\
(\mathrm{s} 3)\end{array}$ & $\begin{array}{c}\text { Slightly low } \\
(\mathrm{s} 4)\end{array}$ & $\begin{array}{c}\text { Low } \\
(\mathrm{s} 5)\end{array}$ & $\begin{array}{c}\text { Very low } \\
(\mathrm{s} 6)\end{array}$ \\
\hline 2010 & 0.000 & 0.000 & 0.014 & 0.280 & 0.414 & 0.004 & 0.000 \\
2011 & 0.000 & 0.000 & 0.020 & 0.450 & 0.201 & 0.001 & 0.000 \\
2012 & 0.000 & 0.000 & 0.007 & 0.159 & 0.414 & 0.005 & 0.000 \\
2013 & 0.000 & 0.000 & 0.012 & 0.341 & 0.420 & 0.004 & 0.000 \\
2014 & 0.000 & 0.000 & 0.012 & 0.296 & 0.500 & 0.005 & 0.000 \\
2015 & 0.000 & 0.000 & 0.011 & 0.281 & 0.514 & 0.005 & 0.000 \\
2016 & 0.000 & 0.000 & 0.004 & 0.167 & 0.688 & 0.010 & 0.000
\end{tabular}


0.000

0.539

0.008

0.000

Note: The value marked with grey color represents the maximum affiliation of the year.

In order to visually show the CSR risk level of Huaneng Group in 2018, the seven standard clouds in Table 2 and the integrated cloud model of Huaneng Group CSR risk in 2018 are shown in Fig 3. In the figure, blue represents standard cloud, and from left to right is standard cloud with very high risk (S0) to very low risk (S6), and it can be observed that the integrated cloud of Huaneng Group in 2018 represented by red is located between the medium risk standard cloud (s3) and the slightly low risk standard cloud (s4).

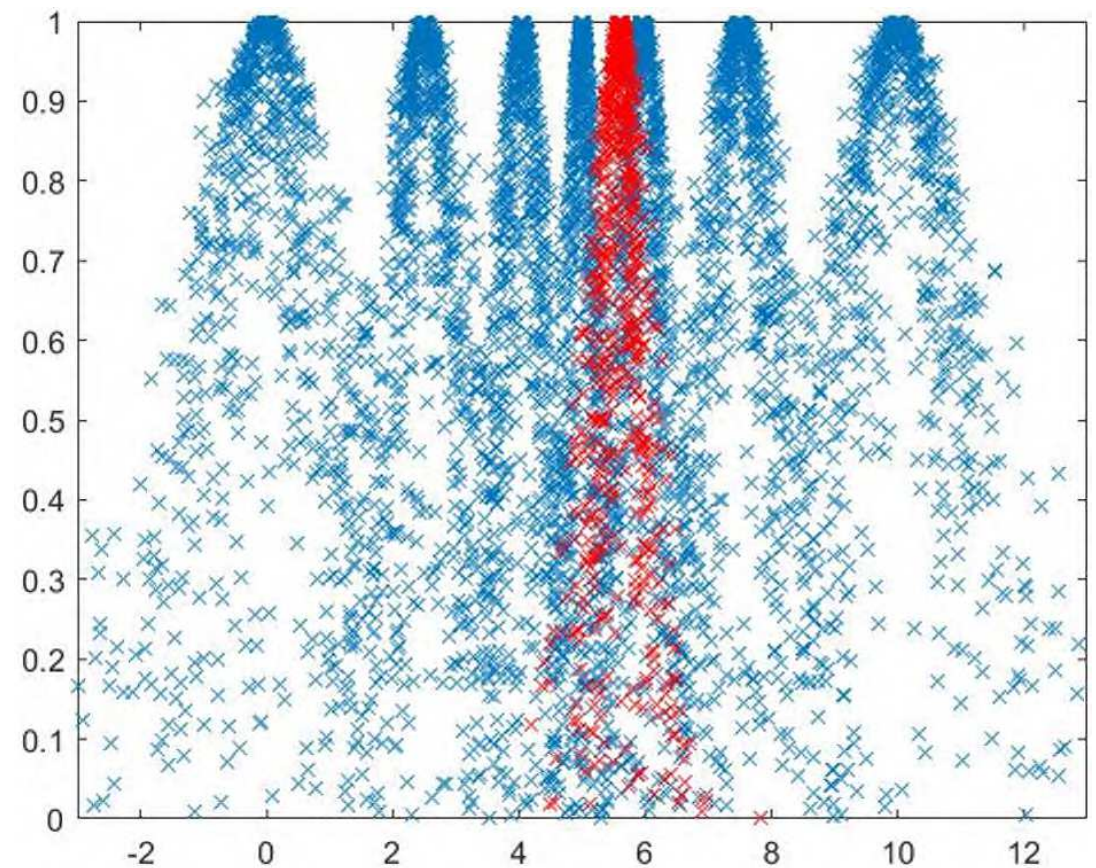

Fig 3. Cloud model of social responsibility risk of Huaneng Group in 2018

\subsection{CSR risk further analysis}

4.4.1 Comparative analysis of specific stakeholders and overall stakeholders

Based on the maximum affiliation principle, the CSR risk levels of Huaneng Group different stakeholders are presented in Table 7. Observing the overall risk at the stakeholder level, except that the CSR risk in 2010 is slightly low (s4), the risk in other years is medium (s3). This paper further makes a comparative analysis of CSR risk between specific stakeholders and overall stakeholders, which considers the heterogeneity of stakeholders and the overall status of CSR risk. It can be found that the CSR risk of $\mathrm{C} 11, \mathrm{C} 13, \mathrm{C} 17$ and $\mathrm{C} 18$ have a higher level in certain years than the overall stakeholders, while the CSR risk of C11, C12, C14, C15 and C17 have a lower level in certain years than the overall stakeholders. The overall Huaneng Group stakeholder risk is relatively high, which is related to the fact that the stakeholders of Huaneng Group are relatively large and complex, and they are closely related to the company. 
In terms of specific stakeholders, the risk level for consumer and community is higher than or equal to the overall risk in all years, and the risk level of community is higher. Huaneng Group should pay more attention to the risk prevention and control of enterprise consumers and communities in the future. In terms of community risk, Huaneng Group should strengthen the public service awareness and promote the benign development with the community.

Table 7. CSR risk level of different stakeholders in Huaneng Group from 2010 to 2018

\begin{tabular}{|c|c|c|c|c|c|c|c|c|c|}
\hline Year & $\begin{array}{c}\text { Shareholder } \\
\text { (C11) }\end{array}$ & $\begin{array}{c}\text { Creditor } \\
\text { (C12) }\end{array}$ & $\begin{array}{c}\text { Consumer } \\
\text { (C13) }\end{array}$ & $\begin{array}{c}\text { Employee } \\
\text { (C14) }\end{array}$ & $\begin{array}{c}\text { Manager } \\
(\mathrm{C} 15)\end{array}$ & $\begin{array}{c}\text { Government } \\
\text { (C16) }\end{array}$ & $\begin{array}{c}\text { Competitor } \\
\text { (C17) }\end{array}$ & $\begin{array}{c}\text { Community } \\
\text { (C18) }\end{array}$ & Overall \\
\hline 2010 & $\mathrm{~s} 2++$ & s4 & s3+ & s4 & s4 & s4 & s4 & s3+ & s4 \\
\hline 2011 & s3 & s3 & s3 & s3 & s3 & s3 & s4- & s3 & s3 \\
\hline 2012 & s4- & s4- & s3 & s4- & s3 & s3 & s4- & s3 & s3 \\
\hline 2013 & s3 & s4- & s3 & s3 & s3 & s3 & s2+ & s2+ & s3 \\
\hline 2014 & s3 & s3 & s3 & s4- & s4- & s3 & s3 & s2+ & s3 \\
\hline 2015 & s3 & s4- & s3 & s4- & s3 & s3 & s3 & s2+ & s3 \\
\hline 2016 & s3 & s3 & s3 & s3 & s4- & s3 & s3 & s3 & s3 \\
\hline 2017 & s3 & s3 & s3 & s4- & s3 & s3 & s3 & s3 & s3 \\
\hline 2018 & s3 & s3 & s3 & s4- & s3 & s3 & s2+ & s3 & s3 \\
\hline
\end{tabular}

Note: "+" indicates that the specific stakeholder risk is one level higher than the overall stakeholder risk; "-" indicates that the specific stakeholder risk is one level lower than the overall stakeholder risk.

4.4.2 Hierarchical analysis of CSR risk indicators at different levels

Table 8 shows the CSR risk level of Huaneng Group at different levels. Observing the legal responsibility risk of Huaneng Group, it is found that the risk is low except in 2011, indicating that Huaneng Group, as a large state-owned enterprise, has undertaken the legal responsibility well. The risk level of environmental responsibility risk in 2010, 2011 and 2017, is medium, while in other years, the risk level is slightly low, and the environmental responsibility risk of Huaneng Group has a decreasing trend. The risk level of charitable risk of Huaneng Group has a decreasing trend, with a slightly lower risk level from 2016 to 2018.

Analyzing the hierarchical relationship of different CSR risk levels of Huaneng Group, it can be found that, from the overall perspective, except that the environmental responsibility risk is higher than the charity responsibility risk in 2017 , in other years the legal responsibility risk level is the lowest in other years, followed by the environmental responsibility risk, and finally the charity responsibility risk, which shows that the CSR risks at different levels of Huaneng Group are relatively balanced.

Table 8. CSR risk level of different levels in Huaneng Group from 2010 to 2018

\begin{tabular}{cccc}
\hline Year & Legal responsibility & Environmental responsibility & Charitable responsibility \\
\hline 2010 & s5 & s3 & s3 \\
2011 & s4 & s3 & s3 \\
2012 & s5 & s4 & s3 \\
2013 & s5 & s4 & s3
\end{tabular}




\subsection{CSR risk management mechanism}

Corporate internal CSR risk management is a prerequisite for effective prevention and control of CSR risks. The CSR management framework mainly includes: the formulation of CSR concepts and strategies, the selection and improvement of key CSR issues, specific CSR control process, and CSR risk assessment (as shown in Fig 4).

i) The key point of CSR risk management is to avoid or minimize losses, and to restore the enterprise as soon as possible after the risk occurs. Under the guidance of the concept and strategy of CSR, a benign interaction between enterprise development and social progress is formed, which is conducive to enterprises to better undertake corresponding obligations for the society and truly realize the win-win situation between enterprises and society.

ii) On the basis of reasonable strategic goals, companies need to set specific control plans at the business-level, determine the focus of CSR work, and select and implement key issues for CSR management. Establish a CSR management committee led by the main person in charge of the company, and the department in charge will be responsible for the overall management of CSR and promote the implementation of CSR related projects.

iii) CSR risk control is an important process of transforming the results of risk identification into risk management measures. CSR risk control measures mainly include the formulation of risk control system and process, the establishment of communication mechanism with stakeholders, and CSR risk training for personnel in key positions.

iv) Through the establishment of CSR risk evaluation index system, the enterprise CSR risk is evaluated, and the key indicators are included in the department performance evaluation standards to promote the implementation of CSR management in specific departments of the enterprise. Through the closed-loop management of goal setting, process tracking and consequence evaluation, the corporate strategic goal of promoting CSR performance is realized. 


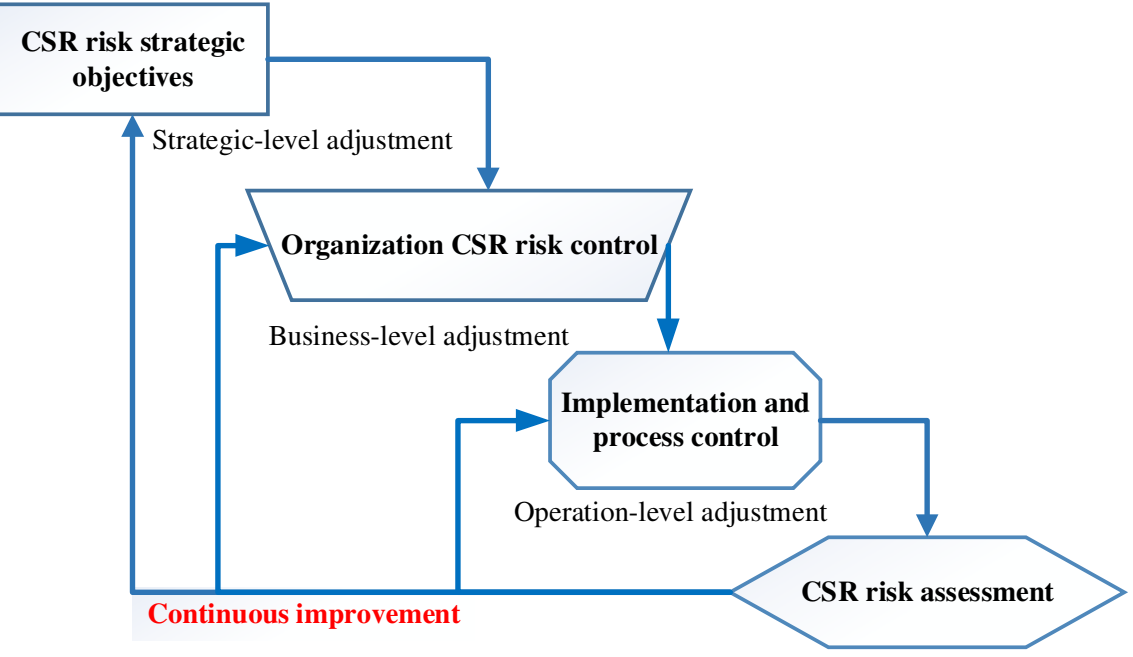

Fig 4. CSR risk management logic diagram

\section{Conclusion}

In this paper, hesitant fuzzy language combined with cloud model is applied in CSR risk assessment for the first time. Hesitant fuzzy language is used to describe the assessment information, and cloud model is applied to complete the quantification process of fuzzy language. This combination method not only considers the hesitation of experts in the process of evaluation, but also takes into account the average value, volatility and dispersion of evaluation results in the process of converting qualitative values into quantitative ones, so as to ensure the complete conversion of information as far as possible. In addition, this model is conducive to the horizontal comparison and dynamic evaluation of CSR risk. Finally, the CSR risk of Huaneng Group from 2010 to 2018 is evaluated, and it is found that CSR risk of Huaneng Group is closest to the slightly low risk standard cloud except for 2011; through further comparative and hierarchical analysis, it is found that Huaneng Group has higher CSR risks in community stakeholders, and lower CSR risks in legal and environmental aspects.

Future suggestions for CSR risk management: i) At the corporate level, as the main organization of CSR risk management, it is necessary to conduct real-time assessment of CSR risk factors to prevent key factors affecting CSR risks. The company decision-makers shall formulate targeted CSR risk control plans according to the relationship between stakeholders and the enterprise, and timely conduct internal CSR risk assessment; pay attention to the hierarchical relationship between law, environment and charitable CSR, make up for the shortcomings of CSR factors, and guarantee sustainable green development of the company. ii) At the industry level, a CSR risk analysis database can be established to dynamically evaluate CSR risks based on authoritative CSR risk evaluation standards and a specialized research team to improve the objectivity and comparability of CSR risk evaluation results. iii) At the government level, strengthen the education and supervision of CSR consciousness, 
and establish scientific and effective CSR supervision methods, increase the cost of corporate non-fulfillment of CSR, and impose timely punishments and disclosures on CSR deficiencies.

\section{Data availability statement}

The data that support the findings of this study are available on request from the corresponding author. The data are not publicly available due to privacy or ethical restrictions.

\section{Compliance with ethical standards}

Conflict of interest The authors have no conflicts of interest to declare that are relevant to the content of this article.

Ethical approval This article does not contain any studies with human participants or animals performed by any of the authors.

\section{Authorship contributions}

Methodology and writing-original draft: Liqi Yi; Conceptualization and resources: Tao Li; Visualization: Yunfen Guo; Writing-review and editing: Ang Li, Ting Zhang and Jing Shen

\section{References}

Abbasbandy S, Hajjari T (2009): A new approach for ranking of trapezoidal fuzzy numbers. Computers \& Mathematics with Applications 57, 413-419

Akremi AE, Gond JP, Swaen V, Roeck KD, Igalens J (2018): How Do Employees Perceive Corporate Responsibility? Development and Validation of a Multidimensional Corporate Stakeholder Responsibility Scale. Journal of Management 44, 619-657

Baek P, Kim T (2021): Socially Responsible HR in Action: Learning from Corporations Listed on the Dow Jones Sustainability Index World 2018/2019. Sustainability 13, 3237

Baofeng YFLLMBS (2020): R esearch on Corporate Social Responsibility Evaluation of Transportation Industry Based on Set Pair Analysis. Management Review 32, 219-234

Carroll AB (1979): A Three-Dimensional Conceptual Model of Corporate Performance. Academy of Management Review 4, 497-505

Carroll AB (1999): Corporate Social Responsibility. Business \& Society 38, 268-295

Chojnacka E, Wiśniewska J (2016): Benefits of Corporate Social Responsibility Engagement in Companies: The Case of Poland. Journal of Management and Business Administration. Central Europe 24

Chuanxi, Zhu, Li, Zhu, Xiaozhi, Zhang (2016): Linguistic hesitant fuzzy power aggregation operators and their applications in multiple attribute decision-making. Information Sciences 367-368, 809-826 
Cl A, Gang KB (2020): A heuristic method to rank the alternatives in the AHP synthesis. Applied Soft Computing

Clarkson M (1998): A Stakeholder Framework for Analysing and Evaluating Corporate Social Performance. The Corporation and Its Stakeholders

Cui L, Chan HK, Zhou Y, Da I J, Lim JJ (2019): Exploring critical factors of green business failure based on Grey-Decision Making Trial and Evaluation Laboratory (DEMATEL). Journal of Business Research 98, 450-461

Deng X, Jiang W (2019): Evaluating Green Supply Chain Management Practices Under Fuzzy Environment: A Novel Method Based on D Number Theory. International Journal of Fuzzy Systems 21, 1389-1402

Dima, JamaliRamez, Mirshak (2007): Corporate Social Responsibility (CSR): Theory and Practice in a Developing Country Context. Journal of Business Ethics 72, 243-262

Farooq Q, Fu P, Liu X, Hao Y (2021): Basics of macro to microlevel corporate social responsibility and advancement in triple bottom line theory. Corporate Social Responsibility and Environmental Management

Galant, Cadez A, Simon (2017): Corporate social responsibility and financial performance relationship: a review of measurement approaches. Ekonomska Istraivanja

Govindan K, Kannan D, Shankar KM (2014): Evaluating the drivers of corporate social responsibility in the mining industry with multi-criteria approach: A multi-stakeholder perspective. Journal of Cleaner Production 84, 214-232

Halkos G, Nomikos S (2021): Corporate social responsibility: Trends in global reporting initiative standards. Economic Analysis and Policy 69, 106-117

Hu-Chen, Liu, Li-En, Wang, ZhiWu, Li, Yu-Ping, Hu (2018): Improving Risk Evaluation in FMEA With Cloud Model and Hierarchical TOPSIS Method. IEEE Transactions on Fuzzy Systems

Hui WU, Wang DP, Zhang Q, Zhang ZD (2015): Evaluation and Comparative Study on Competitiveness of International Cruise Ports Based on Cloud Model. China Soft ence

Husted BW (2005): Risk Management, Real Options, Corporate Social Responsibility. Journal of Business Ethics 60, 175-183

Jian XU, Tian Y, Business SO, University YS (2014): Sustainable Supply Chain Management Perspective Risk Assessment of Corporate Social Responsibility-in the Auto Industry,for Example. Chinese Journal of Management Science

Karaman AS, Akman E (2018): Taking-off corporate social responsibility programs: An AHP application in airline industry. Journal of Air Transport Management 68, 187-197

Kuo YF, Lin YM, Chien HF (2020): Corporate social responsibility, enterprise risk management, and real earnings management: Evidence from managerial confidence. Finance Research Letters, 101805

Li Q, Wang F, Yu Y, Huang Z, Li M, Guan Y (2018): Comprehensive performance evaluation of LID practices for the sponge city construction: A case study in Guangxi, China. Journal of Environmental Management 231, 10-20

Li W, Xu G, Zuo D, Zhu J (2021): Corporate Social Responsibility Performance-Evaluation Based on Analytic Hierarchy Process-Fuzzy Comprehensive Evaluation Model. Wireless Personal Communications, 1-23 
Liao H, Xu Z, Zeng XJ (2014): Distance and similarity measures for hesitant fuzzy linguistic term sets and their application in multi-criteria decision making. Information Sciences $271,125-142$

Liao H, Gou X, Xu Z (2017): A survey of decision making theory and methodologies of hesitant fuzzy linguistic term set. Xitong Gongcheng Lilun yu Shijian/System Engineering Theory and Practice 37, 35-48

Liao PC, Shih YN, Wu CL, Zhang XL, Wang Y (2018): Does corporate social performance pay back quickly? A longitudinal content analysis on international contractors. Journal of Cleaner Production 170, 1328-1337

López M, Rodriguez GL (2007): Sustainable Development and Corporate Performance: A Study Based on the Dow Jones Sustainability Index. Journal of Business Ethics 75, 285-300

Masud M, Rashid M, Khan T, Bae SM, Kim JD (2019): Organizational Strategy and Corporate Social Responsibility: The Mediating Effect of Triple Bottom Line. International journal of environmental research and public health 16, 1-19

Meng B, Niu E, Kuang H, Luo J (2018): An evaluation model and empirical research on CSR based on cloud model. Science Research Management

Nikolaou IE, Evangelinos KI, Allan S (2013): A reverse logistics social responsibility evaluation framework based on the triple bottom line approach. Journal of Cleaner Production 56, 173-184

R F (1984): Strategic Management: A Stakeholder Approach, Cambridge University Press

Rajak S, Vinodh S (2015): Application of fuzzy logic for social sustainability performance evaluation: a case study of an Indian automotive component manufacturing organization. Journal of Cleaner Production 108, 1184-1192

Richardson J, Henriques A (2004): The Triple Bottom Line. The Triple Bottom Line

Tsalis T.A MKE, Koulouriotis D, Nikolaou I.E (2020): New challenges for corporate sustainability reporting: United Nations' 2030 Agenda for sustainable development and the sustainable development goals. Corporate Social Responsibility and Environmental Management 27, 1617-1629

Tseng ML, Wu KJ, Ma L, Kuo TC, Sai F (2017): A hierarchical framework for assessing corporate sustainability performance using a hybrid fuzzy synthetic method-DEMATEL. Technological Forecasting and Social Change, S0040162517305723

Vahdani B, Zandieh M, Roshanaei V (2011): A hybrid multi-stage predictive model for supply chain network collapse recovery analysis: a practical framework for effective supply chain network continuity management. International Journal of Production Research 49, 2035-2060

Valiente JMA, Ayerbe CG, Figueras MS (2012): Social responsibility practices and evaluation of corporate social performance. Journal of Cleaner Production 35, 25-38

Wang J, Zhu J, Liu X (2017): An integrated similarity measure method for normal cloud model based on shape and distance. Xitong Gongcheng Lilun yu Shijian/System Engineering Theory and Practice 37, 742-751 
Wang JQ, Peng JJ, Zhang HY, Tao L, Chen XH (2015): An Uncertain Linguistic Multi-criteria Group Decision-Making Method Based on a Cloud Model. Group Decision \& Negotiation 24, 171-192

Wu Y, Xu C, Li L, Wang Y, Chen K, Xu R (2018): A risk assessment framework of PPP waste-to-energy incineration projects in China under 2-dimension linguistic environment. Journal of Cleaner Production 183, 602-617

Yang B, Lin C, Ren C (2018): Internationalization strategy, social responsibility pressure and enterprise value. Soft Computing, 1-8

Zhao H, Sun J, Hu F, Zhao Y (2012): Corporate social responsibility evaluation index system development based on industry internal perspective. Journal of Tongji University(Natural ence)

Zhou L, Gao K (2020): On some pseudometrics in the intuitionistic fuzzy environment. Soft Computing 